\title{
Primary cilia disappear in rat podocytes during glomerular development
}

\author{
Koichiro Ichimura $\cdot$ Hidetake Kurihara • Tatsuo Sakai
}

Received: 21 January 2010 / Accepted: 14 April 2010/Published online: 22 May 2010

(C) Springer-Verlag 2010

\begin{abstract}
Most tubular epithelial cell types express primary cilia, and mutations of primary-cilium-associated proteins are well known to cause several kinds of cystic renal disease. However, until now, it has been unclear whether mammalian podocytes express primary cilia in vivo. In this study, we determined whether primary cilia are present in the podocytes of rat immature and mature glomeruli by means of transmission electron microscopy of serial ultrathin sections. In immature glomeruli of fetal rats, podocytes express the primary cilia with high percentages at the S-shaped body $(88 \pm 5 \%, n=3)$, capillary loop $(95 \pm 4 \%, n=4)$, and maturing glomerulus $(76 \pm 13 \%, n=5)$ stages. The percentage of ciliated podocytes was significantly lower at the maturing glomerulus stage than at the former two stages. In mature glomeruli of adult rats, ciliated podocytes were not found at all $(0 \pm 0 \%, n=11)$. These findings indicate that the primary cilia gradually disappear in rat podocytes during glomerular development. Since glomerular filtration rate increases during development, the primary cilia on the podocytes are subjected to a stronger bending force. Thus, the disappearance of the primary cilia presumably prevents the entry of
\end{abstract}

Electronic supplementary material The online version of this article (doi:10.1007/s00441-010-0983-7) contains supplementary material, which is available to authorized users.

\footnotetext{
K. Ichimura $(\bowtie) \cdot H$. Kurihara $\cdot$ T. Sakai

Department of Anatomy and Life Structure,

Juntendo University School of Medicine,

2-1-1 Hongo,

Bunkyo-ku, Tokyo 113-8421, Japan

e-mail: ichimura@juntendo.ac.jp

T. Sakai

Sportology Center,

Juntendo University Graduate School of Medicine,

Tokyo, Japan
}

excessive calcium-ions via the cilium-associated polycystin complexes and the disturbance of intracellular signaling cascades in mature podocytes.

Keywords Glomerular epithelial cell · Primary cilium . Glomerulogenesis · Serial ultrathin sections · Rat (Wistar)

\section{Introduction}

The cilium is one of the most elementary cellular organelles and is composed of a ciliary membrane and a microtubulebased axoneme protruding from a basal body. Two kinds of cilium are distinguished on the basis of their structure and function: motile and primary cilia (Satir and Christensen 2007; Wheatley et al. 1996). Motile cilia are densely found in specific epithelial cell types, such as the ciliated cells of respiratory tract, and play a role in escalator transportation on the luminal surface. In this type of cilium, the axoneme is arranged in a $9+2$ pattern, with nine peripheral microtubule-doublets on the periphery surrounding a pair of central microtubule-singlets. On the other hand, the primary cilia are recognized in a variety of cell types, including epithelial, endocrine, and neuronal cell types. There are two ultrastructural characteristics of the primary cilia: (1) the axoneme is arranged in a $9+0$ pattern; and (2) the primary cilium uses the mother centriole of the centrosome as its basal body. The primary cilia serve as cellular mechano- and chemo-sensors, and are immotile except for those on the epithelium around the primitive node of the embryonic disc (Nonaka et al. 1998).

Primary cilia are recognized in most of the epithelial cell types constituting the nephron and collecting duct (Andrews and Porter 1974; Bulger et al. 1974). Mutations in the primary-cilium-associated proteins (polycystin-1, 
Table 1 Percentage of the podocytes expressing a primary cilium in mature glomeruli of adult rats

\begin{tabular}{llllll}
\hline Stage & $\begin{array}{l}\text { Glomeruli } \\
\text { no. }\end{array}$ & \begin{tabular}{l} 
Primary cilium \\
\cline { 3 - 4 }
\end{tabular} & & $\begin{array}{l}\text { Total cell } \\
\text { number }\end{array}$ & $\begin{array}{l}\text { Percentage of } \\
\text { ciliated podocytes }\end{array}$ \\
\hline Mature & 1 & 0 & 13 & 13 & 0 \\
& 2 & 0 & 14 & 14 & 0 \\
& 3 & 0 & 9 & 9 & 0 \\
& 4 & 0 & 8 & 8 & 0 \\
& 5 & 0 & 11 & 11 & 0 \\
& 6 & 0 & 10 & 10 & 0 \\
& 7 & 0 & 14 & 14 & 0 \\
& 8 & 0 & 24 & 24 & 0 \\
& 9 & 0 & 23 & 23 & 0 \\
& 10 & 0 & 11 & 11 & 0 \\
& 11 & 0 & 12 & 12 & 0 \\
Totals & & 0 & 149 & 149 & 0 \\
\hline
\end{tabular}

polycystin-2, and so on) cause the irregularity of spatiotemporal proliferation in the tubular epithelium, and further clinically cause a variety of cystic kidney diseases (Veland et al. 2009; Yoder 2007). Considerable research has thus been done on the primary cilia in renal epithelium in an attempt to determine the mechanism of cystogenesis and develop a treatment for cystic kidney diseases (see RodatDespoix and Delmas 2009 and references therein).

Although the importance of primary cilia has been clarified in tubular epithelial cells, it remains controversial whether glomerular epithelial cells (podocytes) express primary cilia in vivo. Some research seems to contend that the podocytes express no primary cilium (Weinstein et al. 1992). However, other studies report that primary cilia are present on the podocytes in some mammalian (rhesus monkey and dog) (Andrews 1975; Ruffo et al. 1966) and lower vertebrate species (Miyoshi 1978; Ojéda et al. 2003; Zuasti et al. 1983) on the basis of electron-microscope observation. Furthermore, in cultured podocytes, the presence of primary cilia is also controversial (Kreisberg et al. 1978; Weinstein et al. 1992; Yaoita et al. 1995).

In this study, we examined whether primary cilia are present in rat podocytes of mature and immature glomeruli by means of immunohistochemistry of cilium-specific antigens and TEM of serial ultrathin sections. In the immature glomeruli of fetal rats, most of the immature podocytes possessed the primary cilia. However, in the glomeruli of adult rats, we did not find any primary cilia in the mature podocytes. Our present findings indicate that primary cilia disappear in rat podocytes during glomerular development. We also discuss the physiological significance of the primary-cilium disappearance in rat podocytes.

\section{Materials and methods}

\section{Animals}

Six male (6 weeks) and one pregnant Wistar rats were obtained from Charles River Japan (Kanagawa, Japan). Fetal rats were removed from the pregnant rat at day 18 of gestation. All animal experiments were approved by the ethical committee of the university and carried out in compliance with the guidelines for animal experimentation of Juntendo University School of Medicine.

\section{Antibodies}

Mouse monoclonal anti-acetylated- $\alpha$-tubulin IgG (clone 611B-1, working dilution 1:500) and mouse monoclonal
Table 2 Percentage of the podocytes expressing a primary cilium in immature glomeruli of fetal rats

\begin{tabular}{|c|c|c|c|c|c|c|}
\hline \multirow[t]{2}{*}{ Stage } & \multirow{2}{*}{$\begin{array}{l}\text { Glomeruli } \\
\text { no. }\end{array}$} & \multicolumn{2}{|c|}{ Primary cilium } & \multirow{2}{*}{$\begin{array}{l}\text { Total cell } \\
\text { number }\end{array}$} & \multirow{2}{*}{$\begin{array}{l}\text { Percentage of } \\
\text { ciliated podocytes }\end{array}$} & \multirow{2}{*}{$\begin{array}{l}\text { Average } \\
\text { percentage }\end{array}$} \\
\hline & & Present & Absent & & & \\
\hline \multirow[t]{3}{*}{ S-shaped body } & 1 & 10 & 2 & 12 & 83 & \multirow[t]{3}{*}{88} \\
\hline & 2 & 18 & 2 & 20 & 90 & \\
\hline & 3 & 11 & 1 & 12 & 92 & \\
\hline \multirow[t]{4}{*}{ Capillary loop } & 4 & 11 & 1 & 12 & 92 & \multirow[t]{4}{*}{95} \\
\hline & 5 & 14 & 1 & 15 & 93 & \\
\hline & 6 & 21 & 1 & 22 & 95 & \\
\hline & 7 & 28 & 0 & 28 & 100 & \\
\hline \multirow[t]{5}{*}{ Maturing } & 8 & 16 & 3 & 19 & 84 & \multirow[t]{5}{*}{76} \\
\hline & 9 & 14 & 1 & 15 & 93 & \\
\hline & 10 & 18 & 8 & 26 & 69 & \\
\hline & 11 & 11 & 4 & 15 & 73 & \\
\hline & 12 & 15 & 10 & 25 & 60 & \\
\hline Totals & & 187 & 34 & 221 & & 85 \\
\hline
\end{tabular}




\section{Actin filaments}
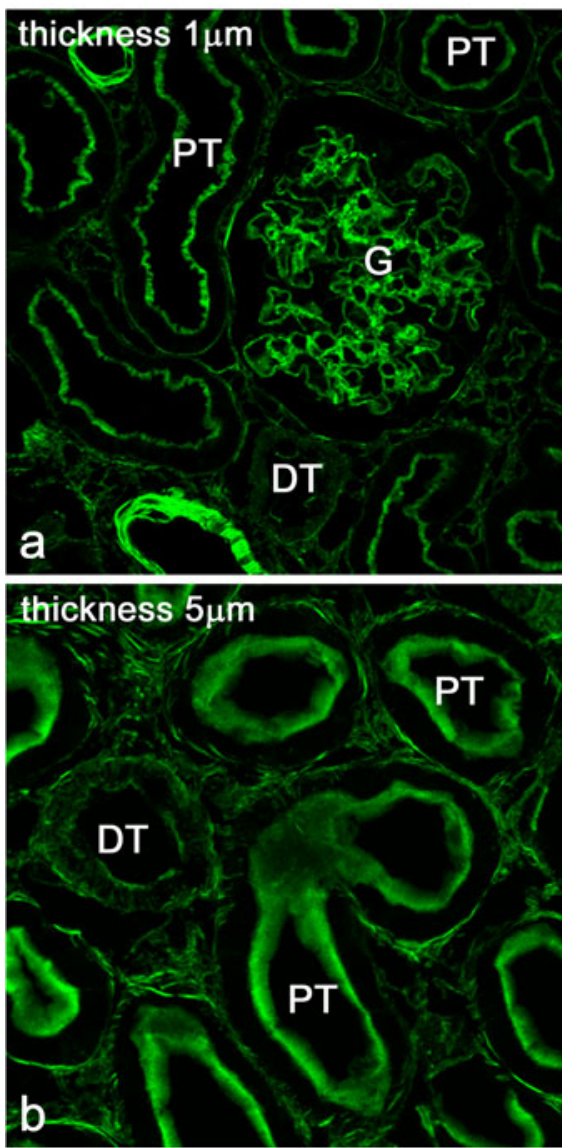

Podocalyxin

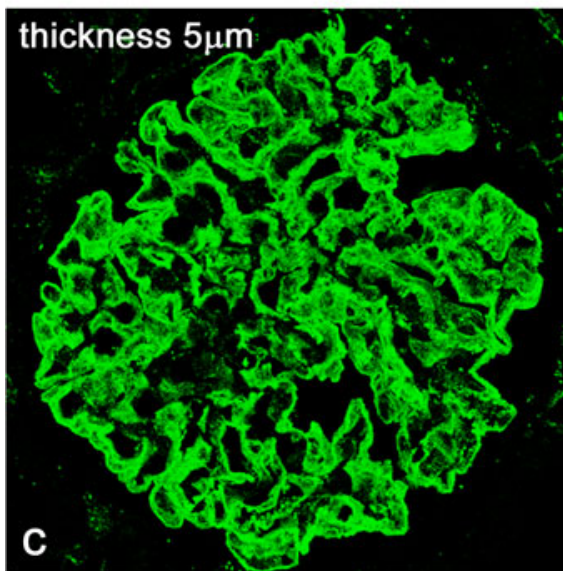

Acetylated $\alpha$-tubulin
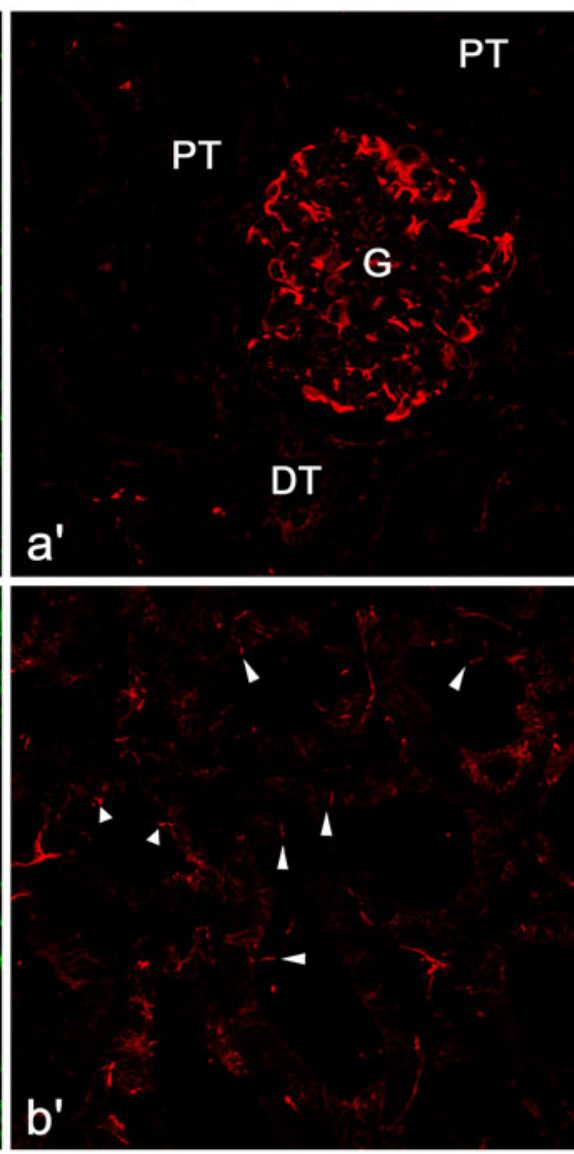

Acetylated $\alpha$-tubulin

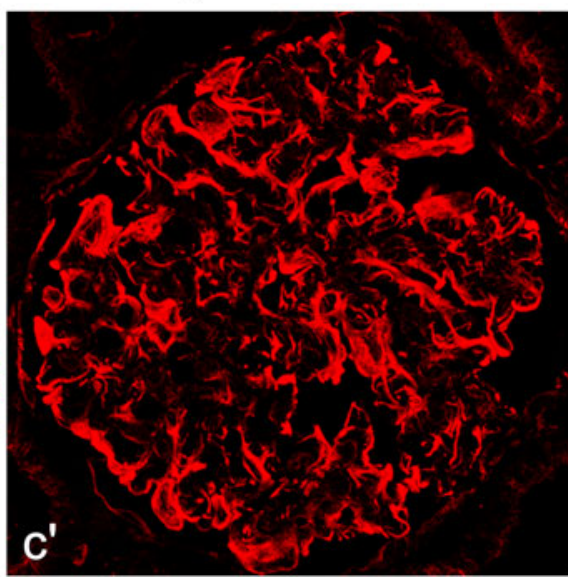

Merge
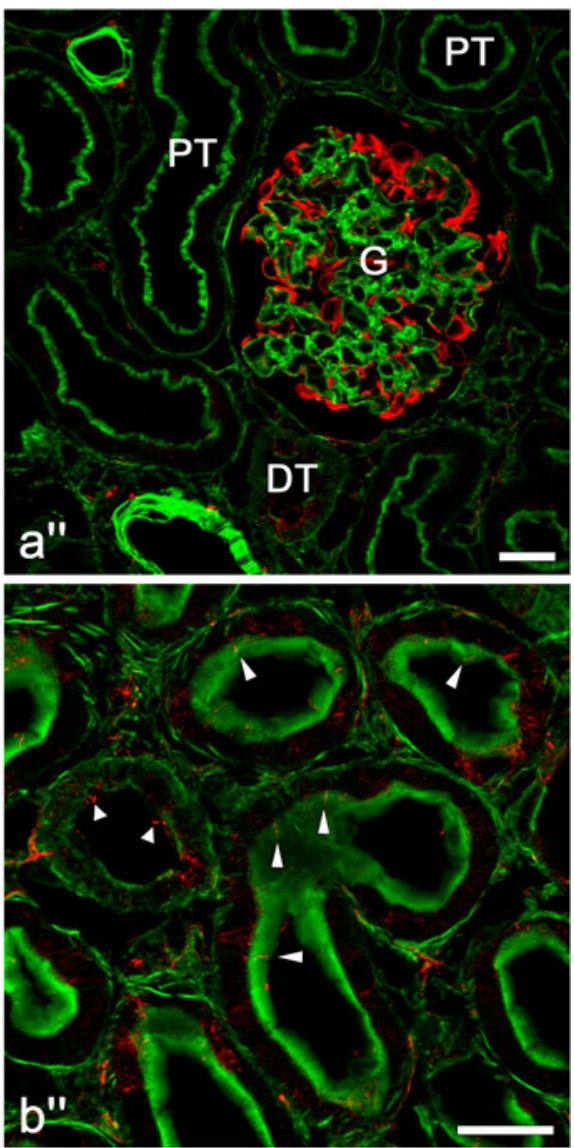

\section{Merge}

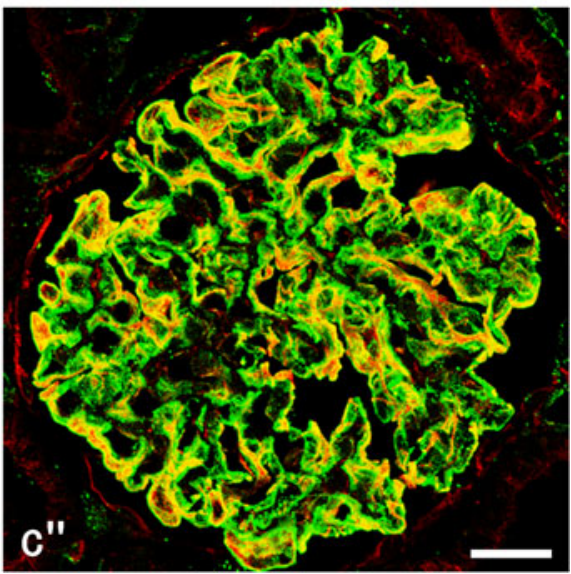

Fig. 1 Immunofluorescence labeling for acetylated $\alpha$-tubulin (Ac-tub, red) in adult rat kidney. a-a" Strong immunofluorescence signal for Ac-tub is found in the glomerulus $(G)$. Such strong signal is not found in the proximal tubules $(P T)$ and distal tubules $(D T)$. Actin filaments are visualized with FL-phallacidin (green) for identification of glomerulus, tubules, and vasculature. $\mathbf{b}-\mathbf{b}^{\prime \prime}$ In the proximal and distal tubules, the primary cilia (arrowheads) are detected with the anti-Ac- tub antibody at the luminal surface. $\mathbf{c}-\mathbf{c}^{\prime \prime}$ In the glomerulus, immunofluorescence signal for Ac-tub (red) is largely colocalized with that for podocalyxin (green), which is predominantly localized at the apical surface membrane of podocytes. It is difficult to determine whether or not the mature podocytes of adult rats possess the primary cilia in this staining. $\mathbf{b}-\mathbf{b}^{\prime \prime}, \mathbf{c}-\mathbf{c}^{\prime \prime}$ Z-stacked images of $5 \mu \mathrm{m}$ thickness. Bars $20 \mu \mathrm{m}$ 


\section{Podocalyxin}
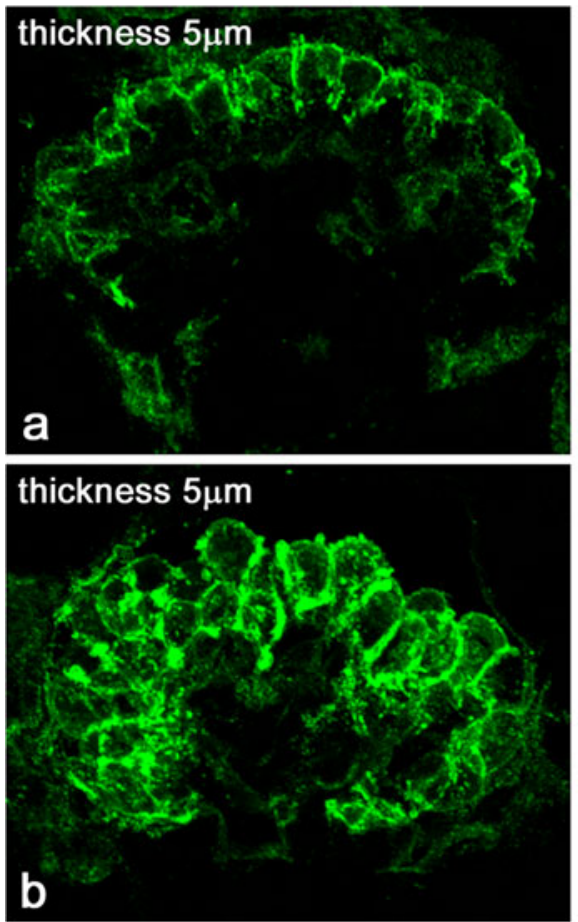

Acetylated $\alpha$-tubulin
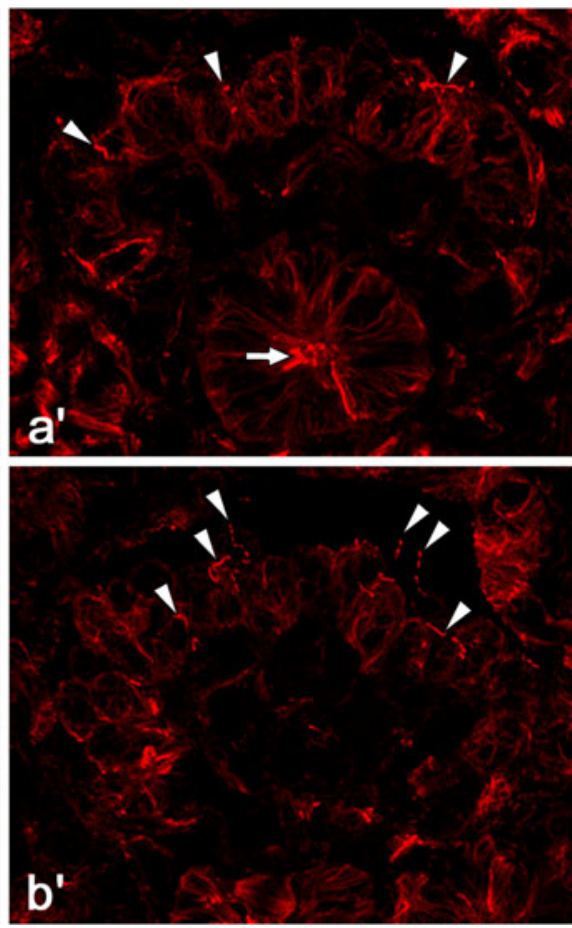

Merge
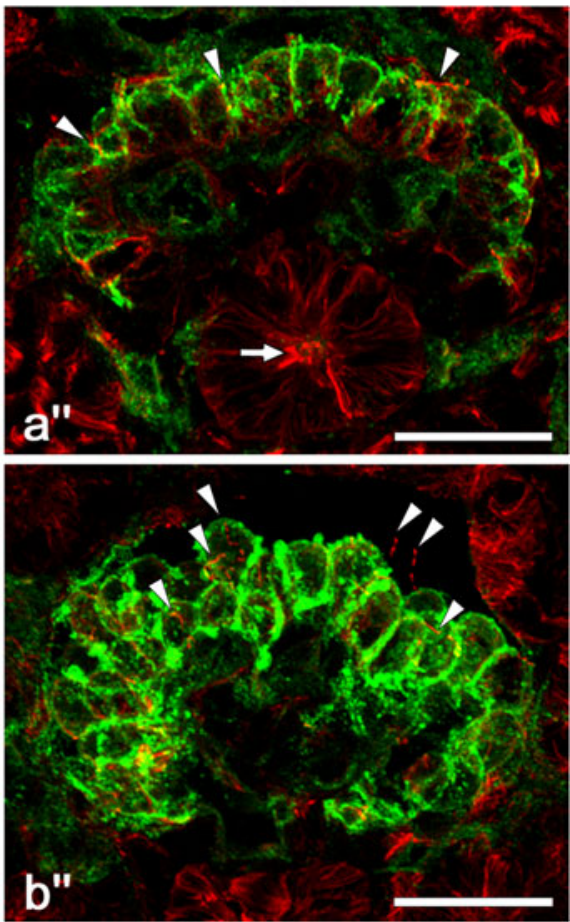

Fig. 2 Immunofluorescence labeling for Ac-tub (red) in fetal rat kidney. Unlike adult kidneys, immunofluorescence intensity of Ac-tub signals is as low in the glomeruli as in the tubules. However, prominent Ac-tub signals like little pieces of thread (arrowheads) are frequently recognized between or on the immature columnar podocytes, whose

anti-detyrosinated- $\alpha$-tubulin IgG (clone 1D5, 1:50) were from Sigma-Aldrich (St. Louis, MO) and Synaptic Systems (Gottingen, Germany), respectively. Rabbit polyclonal antipodocalyxin antibody (1:500) was raised against the glutathione S-transferase fusion protein with the entire cytoplasmic domain of rat podocalyxin (Kobayashi et al. 2009). TRITC-conjugated donkey anti-mouse $\operatorname{IgG~} \mathrm{F}\left(\mathrm{ab}^{\prime}\right)_{2}$ fragment (1:200) and FITC-conjugated donkey anti-rabbit $\operatorname{IgG~} \mathrm{F}\left(\mathrm{ab}^{\prime}\right)_{2}$ fragment $(1: 100)$ were from Jackson ImmunoResearch Laboratories (West Grove, PA).

\section{Confocal laser scanning microscopy}

Three adult and four fetal rats were perfused with $4 \%$ paraformaldehyde fixative buffered with $0.1 \mathrm{M}$ phosphate buffer under anesthesia with pentobarbital. The perfused kidneys were cut into small pieces, and immersed in the same fixative for about $30 \mathrm{~min}$. After washing with PBS, the samples were immersed successively in PBS containing 10,15 , and $20 \%$ sucrose for 4 , 12 , and $4 \mathrm{~h}$, respectively. Subsequently, the samples were frozen in OCT compound (Sakura Finetechnical, Tokyo, Japan), and cut into $10-\mu \mathrm{m}$-thick cryosections with a 2800E Jung Frigocut (Leica, Wetzlar, Germany). After mounting on aminosilane-coated glass slides (Matsunami apical membrane is labeled with anti-podocalyxin antibody (green). Similar signals of Ac-tub are also found in the lumen of immature tubules (arrows). These thread-like signals for Ac-tub presumably represent the primary cilia. a-a" Late S-shaped body stage. b-b" Capillary loop stage. Z-stacked images of $5 \mu \mathrm{m}$ thickness. Bars $20 \mu \mathrm{m}$

Glass Industry, Osaka, Japan), the sections were washed with PBS, blocked with blocking solution $(0.1 \%$ bovine serum albumin in PBS), and incubated for $2 \mathrm{~h}$ with the anti- $\alpha$-tubulin (6-11B-1 or 1D5) and anti-podocalyxin antibodies diluted with the blocking solution. After washing with blocking solution, the sections were incubated for $1 \mathrm{~h}$ with the fluorescence dye-conjugated secondary antibodies diluted with the blocking solution. Some sections were double-stained with the anti- $\alpha$ tubulin antibody (6-11B-1 or 1D5) and BODIPY FL phallacidin (FL-P, 1:200; Molecular Probes, Eugene, OR), which is specifically labeled actin filaments. The fluorescence specimens were observed with a LSM510 META confocal laser scanning microscope (Carl Zeiss, Oberkochen, Germany). As the negative control experiment, the primary antibodies were either omitted from the incubation solution or substituted with normal mouse IgG or normal rabbit serum at the same concentrations as the primary antibodies.

\section{Transmission electron microscopy}

Three adult and two fetal rats were perfused with $2.5 \%$ glutaraldehyde fixative buffered with $0.1 \mathrm{M}$ phosphate buffer under anesthesia with pentobarbital. The perfused 

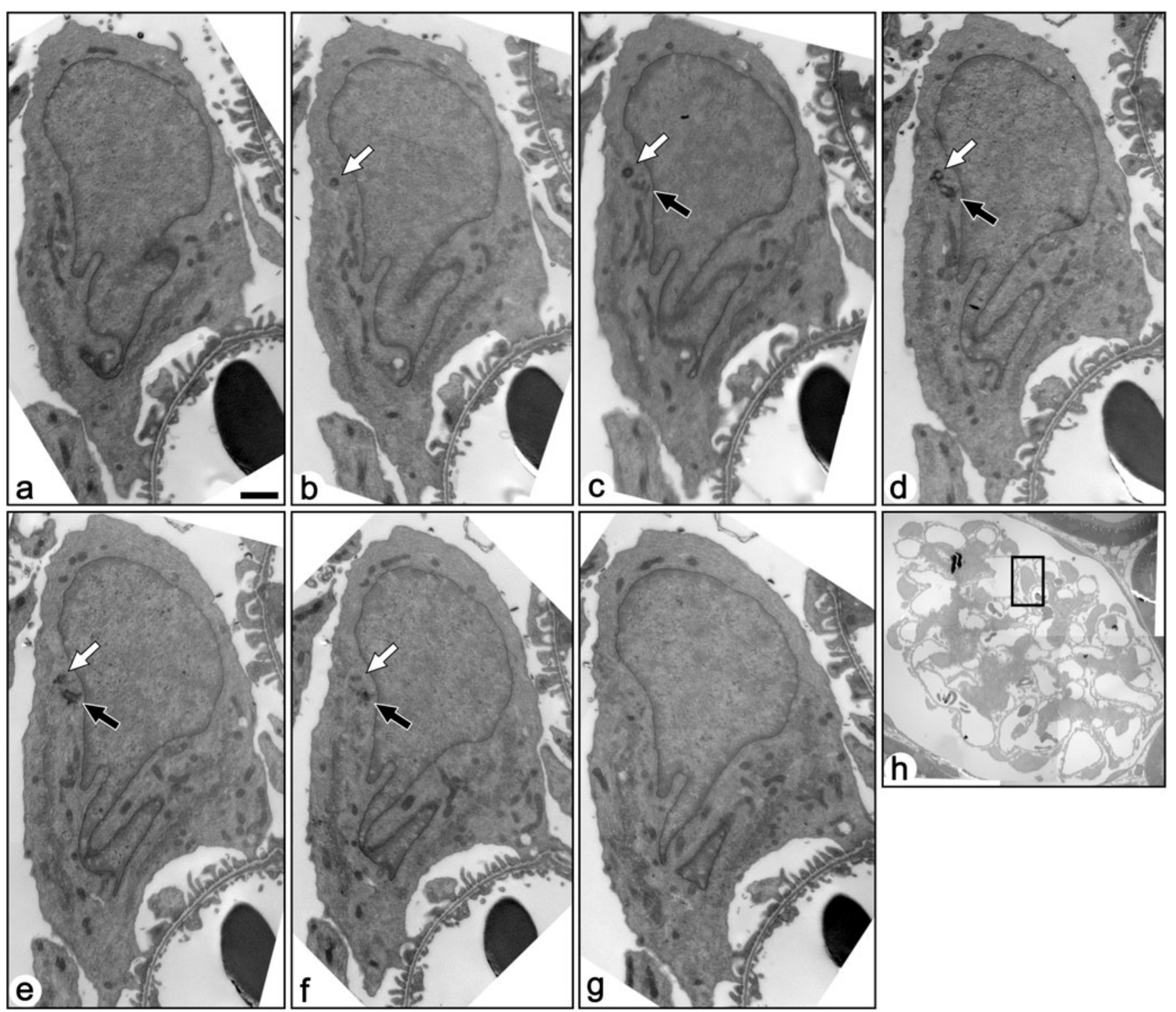

Fig. 3 Serial transmission electron micrographs of a mature podocyte in adult rat (a-g). These sections include both the mother (solid arrows) and daughter (open arrows) centrioles, which are located near the nucleus. The mother centriole is not in touch with the surface plasma

kidneys were cut into small blocks and immersed in the same fixative for a few days. The blocks were cut into $250-\mu \mathrm{m}$-thick slices with a DTK-1000 Microslicer (Dosaka EM, Kyoto, Japan), and the slices were processed by modified cold dehydration method. This method enabled detailed morphological observation of the extracellular matrices and cytoskeletons including microtubules, as reported previously (Ichimura et al. 2007, 2009). In brief, the slices were successively immersed in $0.4 \% \mathrm{OsO}_{4}$ in $0.1 \mathrm{M}$ phosphate buffer for $1 \mathrm{~h}, 2 \%$ low molecular weight tannic acid (Electron Microscopy Sciences, Hatfield, PA) in $0.05 \mathrm{M}$ maleate buffer for $4 \mathrm{~h}$, and $1 \%$ uranyl acetate in $0.05 \mathrm{M}$ maleate buffer for $3 \mathrm{~h}$. The slices were then membrane, and no primary cilium was projected from the mother centriole. Bar $1 \mu \mathrm{m}$. h The podocyte shown by the serial sections is located in the rectangle

dehydrated with a graded series of cold acetone, and were embedded in Epon 812. In each rat, 150-200 serial ultrathin sections (90-100 nm thickness) containing two to six glomeruli were produced with an ultra $45^{\circ}$ diamond knife (Diatome, Biel, Switzerland). The serial ultrathin sections were transferred to copper grids (50 mesh) which had been coated with Formvar membrane. The serial sections without electron staining were digitally photographed with a H-7100 transmission electron microscope (Hitachi High-Technologies, Tokyo) which was equipped with a C4742-95 CCD camera (Hamamatsu Photonics, Shizuoka, Japan). The numbers of glomeruli and podocytes examined are shown in Tables 1 and 2. 
Fig. 4 Transmission electron micrographs of centrioles and associated structures in the mature podocytes of adult rats. Axial (a-c) and longitudinal $(\mathbf{d}, \mathbf{e})$ sections of mother centrioles show transitional fibers (arrowheads) and basal feet (arrows). Even in the case where the mother centriole is close to the surface plasma membrane, the transitional fibers are not in contact with the membrane as indicated by arrowheads in (e). a-c Axial serial sections. f,g Striated rootlets (arrows) are occasionally found near the centrioles. $G$ Golgi apparatus, $N$ nucleus. Bars $500 \mathrm{~nm}$
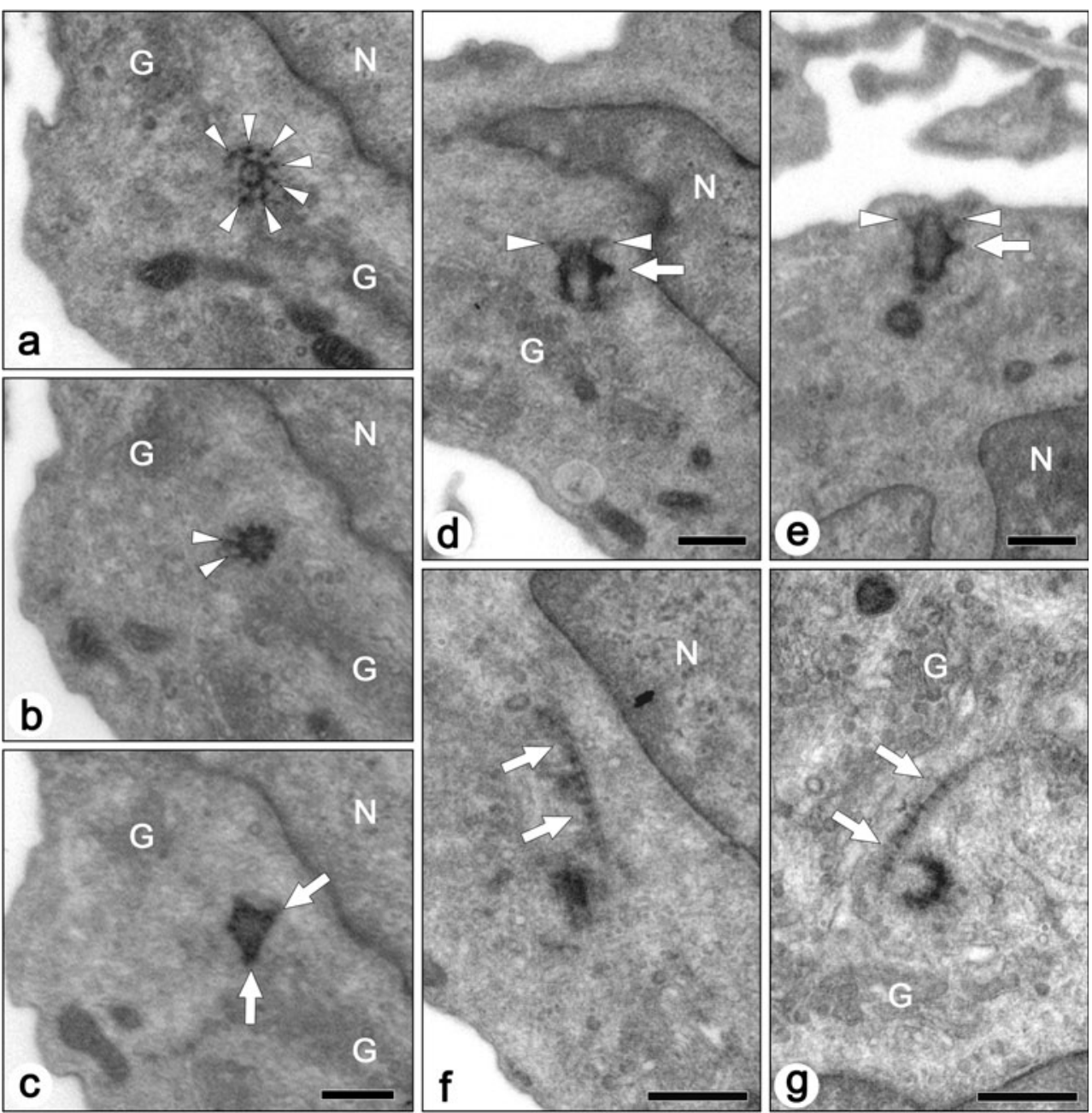

\section{Statistical analysis}

Values are presented as means $\pm \mathrm{SD}$. Differences were tested using Student's $t$ test, with $p<0.05$ being considered significant.

\section{Results}

Immunohistochemical detection of the primary cilia on podocytes

We used specific antibodies to acetylated $\alpha$-tubulin (Actub, clone 6-11B-1) and detyrosinated $\alpha$-tubulin (Detyr-tub, clone $1 \mathrm{D} 5)$ for the detection of the primary cilia in mature and immature glomeruli of adult (6 weeks) and fetal (embryonic day 18 ) rats. $\alpha$-Tubulin in the ciliary axoneme is highly acetylated and detyrosinated, and thus the monoclonal antibodies to Ac-tub or Detyr-tub have been frequently used for the immunohistochemical detection of the primary cilia in a variety of cell types (Lu et al. 2008; Poole et al. 2001; Wheatley 1995).
In the renal cortex of adult rats, the immunofluorescence signals for both Ac-tub and Detyr-tub were predominantly found at the glomeruli (Fig. 1a-a"; Electronic supplementary material, ESM, Fig. S1a-a"). Such prominent signals in the glomeruli were derived from the podocytes, since these signals were found in the glomerulus-forming cells expressing podocalyxin, an apical cell membrane protein of podocytes (Fig. 1c- $\mathrm{c}^{\prime \prime}$; ESM, Fig. S1c- $\left.c^{\prime \prime}\right)$. In mature podocytes, the signals for Ac-tub and Detyr-tub were widely distributed within the cell bodies and primary processes. It was therefore difficult to determine whether or not mature podocytes possess the primary cilia by means of the immunohistochemistry of Ac-tub and Detyr-tub. On the other hand, the primary cilia on tubular epithelial cells were easily detected by the antibodies, as reported previously (arrowheads in Fig. 1b-b"; ESM, Fig. S1b-b") (Verghese et al. 2008, 2009; Wang et al. 2008).

Unlike mature glomeruli in adult rats, the immunofluorescence intensity of Ac-tub and Detyr-tub was much lower in the immature glomeruli of rat fetuses, whose kidneys exhibited all stages of glomerulogenesis except for the 

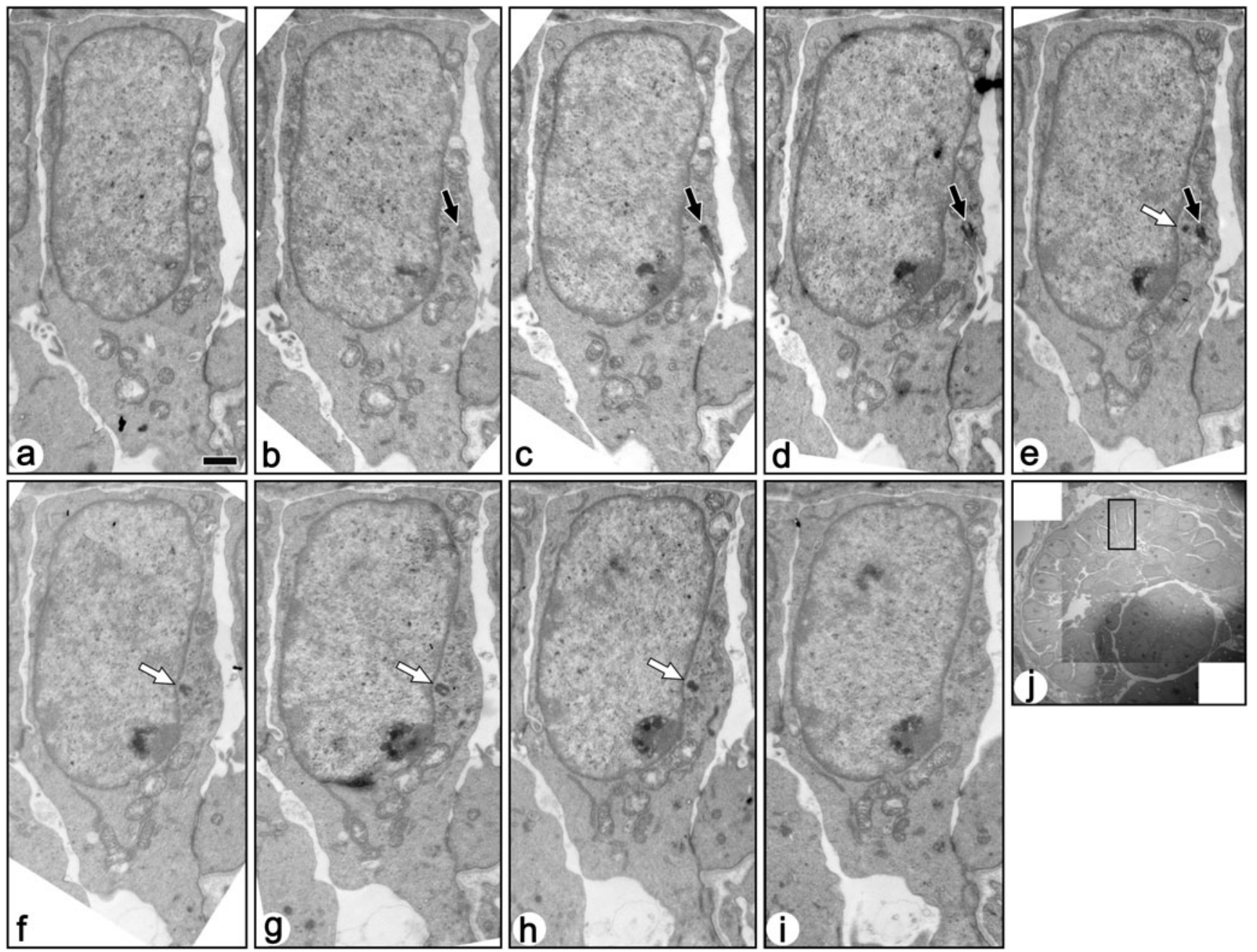

Fig. 5 Serial transmission electron micrographs of a ciliated immature podocyte in fetal rat (a-i). These sections include both basal body/ mother centriole (solid arrows) and daughter centriole (open arrows). A primary cilia protruded from the bottom of shallow recess, and the basal

body/mother centriole is located beneath the bottom membrane of the recess. Bar $1 \mu \mathrm{m}$. j The podocyte shown by the serial sections is located in the rectangle

completely mature stage (Fig. 2; ESM, Fig. S2). However, Ac-tub and Detyr-tub signals, which looked like little pieces of red thread, were frequently recognized between or on the immature podocytes at the S-shaped body and capillary loop stages (arrowheads in Fig. 2; ESM, Fig. S2), and the maturing glomerulus stages (data not shown). These thread-like signals for Ac-tub or Detyr-tub presumably represented the primary cilia.

Electron-microscopic detection and quantification of the primary cilia on podocytes

The immunohistochemistry of Ac-tub or Detyr-tub was not suitable to determine whether mature podocytes express the primary cilia. We thus examined the serial ultrathin sections containing entire centrosome and associated structures of the mature podocytes, since the primary cilium utilizes the mother centriole of centro-

some as the basal body. We observed the serial sections of centrosomes for 149 mature podocytes, which were derived from 11 glomeruli of three adult rats. None of the 149 mature podocytes expressed the primary cilium whose axoneme protruded from the mother centriole (solid arrows in Fig. 3; Table 1).

In most cases of mature podocytes, the centrosome was located away from the surface plasma membrane and surrounded by the Golgi apparatus. We could easily distinguish between the mother and daughter centrioles in the serial ultrathin sections, since the mother centriole was associated with six transient fibers at the distal end and two or three basal feet on the side, as previously reported in other cell types (Fig. 4a-d) (Wheatley 1982). In rare cases, the distal end of the mother centriole was beneath the surface plasma membrane, but the transient fibers, which are involved in the connection between the mother centriole/basal body and the plasma membrane, were not 

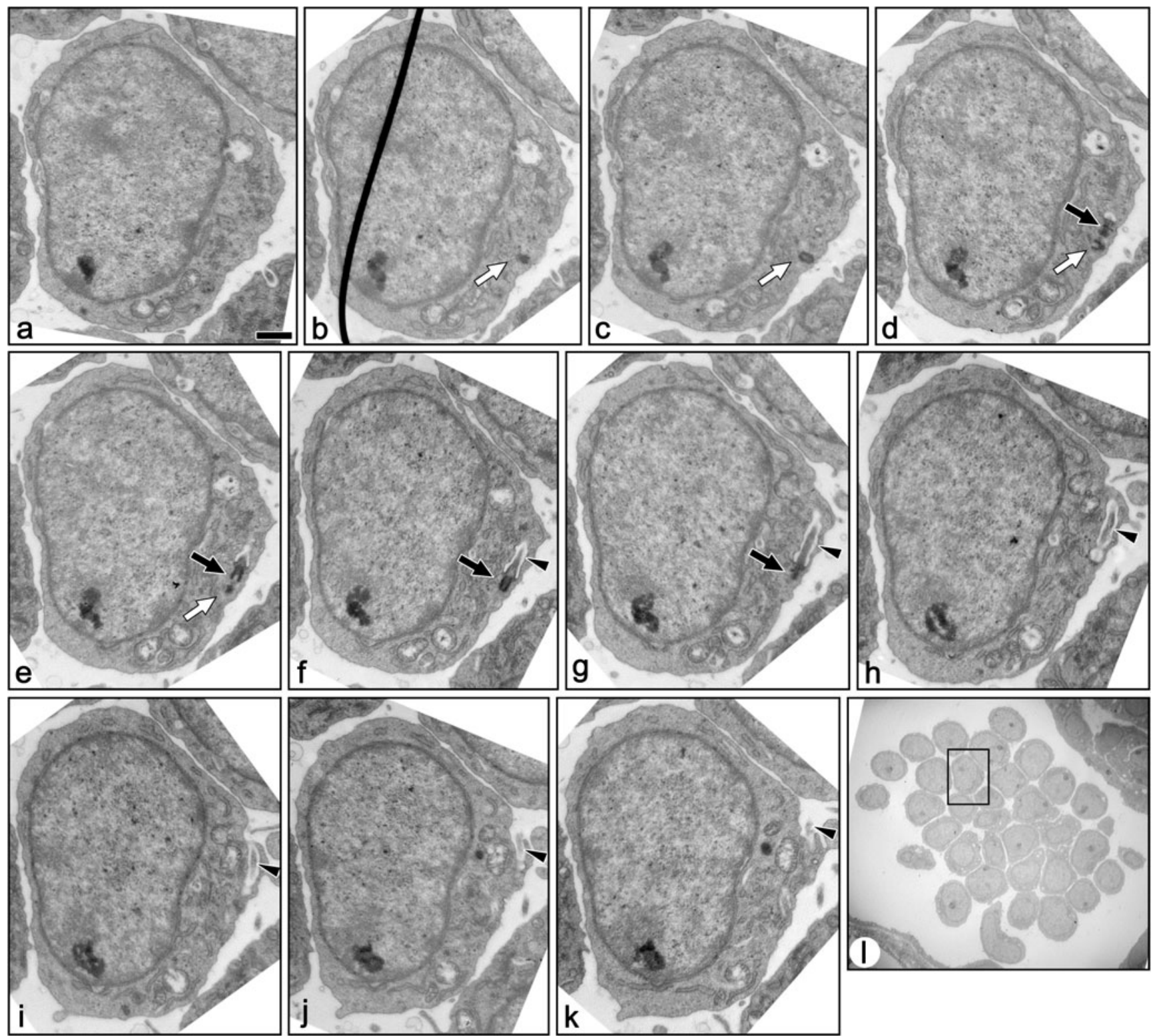

Fig. 6 Serial transmission electron micrographs of a ciliated immature podocyte in fetal rat $(\mathbf{a}-\mathbf{k})$. These sections include both basal body/mother centriole (solid arrows) and daughter centriole (open arrows). In this case, the recess is very deep and forms a sheath-like invagination. Most part of

in direct contact with the plasma membrane (Fig. 4e). The striated rootlet(s), which were $50-650 \mathrm{~nm}$ in length, was occasionally found near the centrosome, although the mature podocytes did not express the primary cilia (Fig. 4f, g).

Unlike the mature podocytes, the immunohistochemistry of Ac-tub and Detyr-tub suggested that the immature podocytes in fetal glomeruli expressed the primary cilia. For confirmation, we observed the serial ultrathin sections containing entire centrosome and associated structures for 221 immature podocytes, which were derived from 12 glomeruli of two fetal rats. Of all the primary cilium is located in the sheath-like invagination (arrowheads). Bar $1 \mu \mathrm{m}$. I The podocyte shown by the serial sections is located in the rectangle

the immature podocytes observed, 187 (85\%) expressed the primary cilium whose axoneme protruded from the mother centriole (Figs. 5 and 6; Table 2).

The percentage of ciliated podocytes was different among the stages of glomerular development (Fig. 7, Table 2). The immature podocytes expressed primary cilia with high percentages at the S-shaped body stage $(88 \pm 5 \%, \mathrm{n}=3)$ and the capillary loop stage $(95 \pm 4 \%, n=4)$. The percentage significantly decreased at the maturing glomerulus stage $(76 \pm 13 \%, \mathrm{n}=6)$, in comparison with the former two stages.

The length of the primary cilia ranged approximately from 0.5 to $7.5 \mu \mathrm{m}$ in the immature podocytes. In most cases, the 


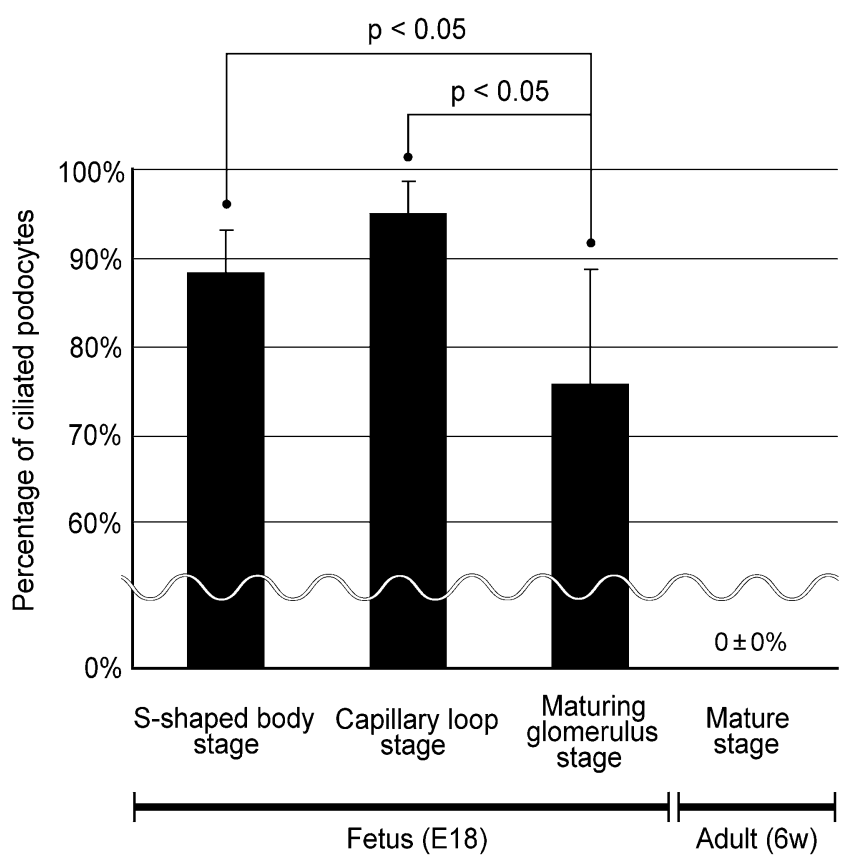

Fig. 7 Percentage of the ciliated podocytes in fetal and adult rat glomeruli. In fetal rat kidneys, the immature podocytes expressed primary cilia with high percentages at the S-shaped body $(88 \pm 5 \%$, $n=3)$ and capillary loop stages $(95 \pm 4 \%, n=4)$. The percentage significantly decreased at the maturing glomerulus stage $(76 \pm 13 \%$, $n=5$ ), in comparison with the former two stages. At the mature stage in adult kidneys, the podocytes express no primary cilia $(0 \pm 0 \%, n=$ 11). The numbers of glomeruli and podocytes examined are shown in Tables 1 and 2. $p<0.05$ was considered significant

primary cilium protruded from a membrane recess of the cell body surface (Figs. 6 and 8a). The recess was sometimes very deep and contained almost whole primary cilium (arrowheads in Fig. 6). The basal body was associated with the transitional fibers and the basal feet, and was surrounded by the Golgi apparatus, as reported previously in other cell types (Fig. 8a, b) (Hagiwara et al. 2008; Wheatley 1982; Yamamoto and Kataoka 1986). The striated rootlets were frequently found in the immature podocytes unlike mature podocytes, and their maximum length was about $800 \mathrm{~nm}$ (Fig. 8c, d). In the immature podocytes without the primary cilia, the mother centrioles were also found near the surface plasma membrane (solid arrows in Fig. 9).

\section{Discussion}

Until now, it has been unclear whether or not podocytes express the primary cilia in vivo. In the present study, by means of TEM of serial ultrathin sections, we clarified that: (1) most of the immature podocytes in fetal rats expressed the primary cilia; (2) the primary cilia on the podocytes gradually disappeared depending on the stage of glomerular development; and (3) the mature podo- cytes in adult rats completely lost the primary cilia (summarized in Fig. 10).

The primary cilia in tissues and cultured cells have been detected by the use of several methods, e.g., SEM, TEM, and immunological detection of cilium-specific antigens including Ac-tub and Detyr-tub (Wheatley 1995). Among these methods, TEM of serial ultrathin sections is the most reliable method for both identification and quantification of the primary cilia (Wheatley 1995). However, only a few researchers have adopted this method (Elofsson et al. 1984; Karlsson 1966; Sasano 1986), since it takes a great deal of time and effort both to make serial ultrathin sections and to observe them. In the present study, we could save several steps including electron staining and film processing by the use of a CCD camera, which is capable of obtaining the digital images from the non-stained ultrathin sections.

The specific antibodies to Ac-tub and Detyr-tub are frequently used for the detection of the primary cilia in both tissues and cultured cells ( $\mathrm{Lu}$ et al. 2008; McGlashan et al. 2006; Wheatley 1995). In most cell types including tubular epithelial cells, these antibodies are useful to detect the primary cilia, as reported previously (Verghese et al. 2008, 2009; Wang et al. 2008). However, in the mature podocytes, prominent immunofluorescence signals for Actub and Detyr-tub were found throughout the cell body and primary processes. It was therefore difficult to determine whether or not the mature podocytes expressed the primary cilia by these antibodies.

Acetylation and detyrosination of $\alpha$-tubulin are posttranscriptional modifications, and proceed gradually after microtubule assembly (see Fukushima et al. 2009 and references therein). Thus, the high content of Ac-tub and Detyr-tub, as seen in the mature podocytes, represents sustained presence and stability of the microtubules, although the acetylation and detyrosination of $\alpha$-tubulin do not contribute to the stabilization of microtubules (Khawaja et al. 1988; Palazzo et al. 2003). The microtubules containing Ac-tub provide a scaffold for the motor protein kinesin-1, and contribute to anterograde transport of vesicles in neuronal cells (Bulinski 2007; Reed et al. 2006). The stable microtubules with high content of Ac-tub presumably play an important role in ensuring the morphological and functional integrity in the mature podocytes. However, the biological significance on the stabilization and posttranscriptional modifications of microtubules in podocytes has yet to be elucidated.

The disappearance of primary cilia in podocytes during glomerular development suggests that the mature podocytes in adult glomeruli are adapted to the peculiar environment which induces the disappearance of primary cilia. Since the glomerular filtration rate (GFR) increases during development, the primary cilia on the immature 
Fig. 8 Transmission electron micrographs of centrioles and associated structures in the immature podocytes of fetal rats. a In most cases, a primary cilium protruded from the bottom of the membrane recess. b A longitudinal section of a basal body/mother centriole shows transitional fibers (arrowheads) and a basal foot (arrow). In ciliated podocytes, the basal body/mother centriole is located beneath the bottom of the membrane recess, and the transitional fibers are in contact with the inner side of the bottom membrane. c,d The striated rootlets (arrows) are frequently found near centrioles. $G$ Golgi apparatus, $N$ nucleus. Bar $1 \mu \mathrm{m}$ (a, c), $200 \mathrm{~nm}(\mathbf{b}, \mathbf{d})$

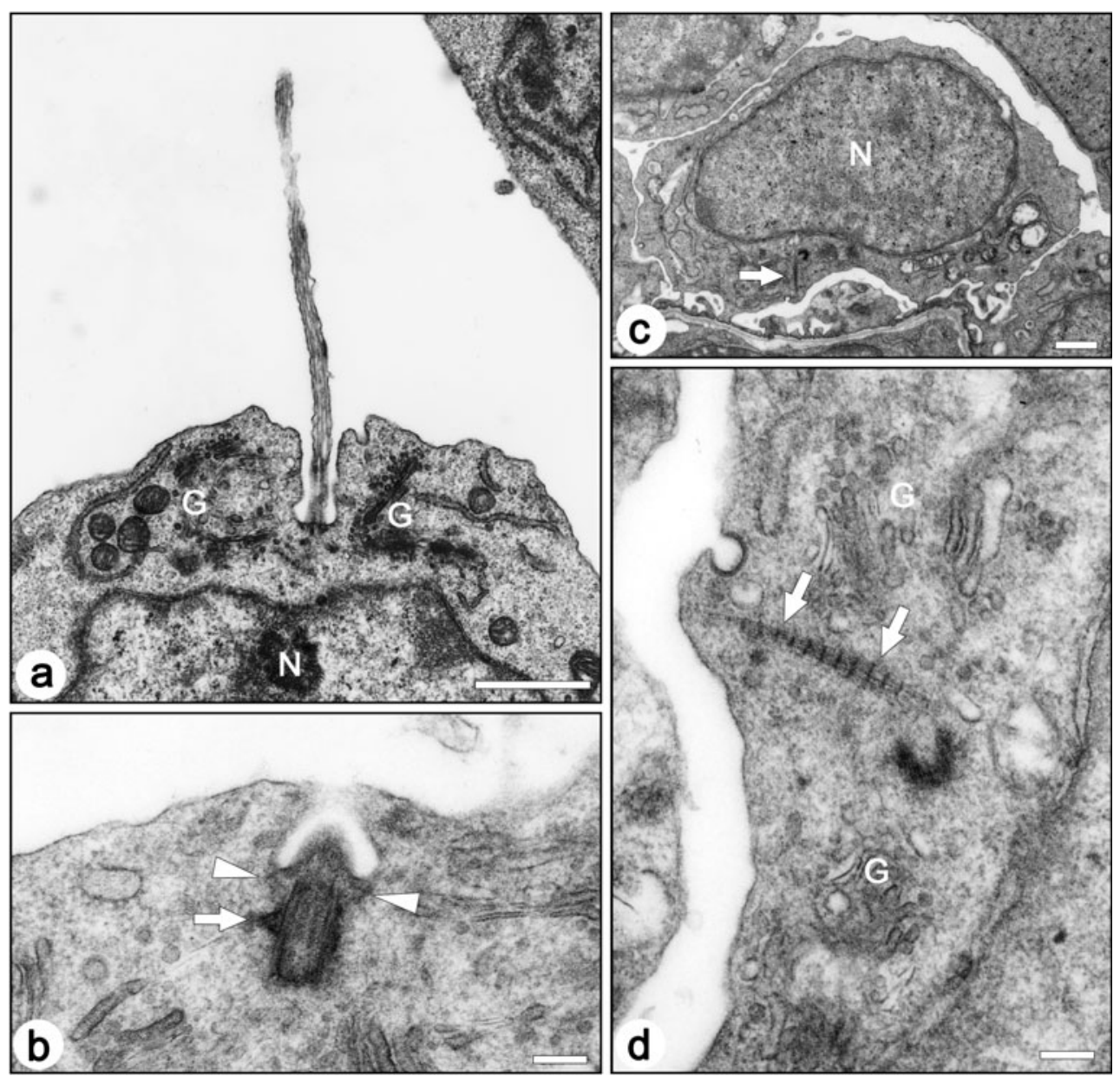

podocytes are subjected to a stronger bending force, and it is highly likely that the influx of calcium ion via the polycystin complexes is increased in the immature podocytes. Therefore, the disappearance of primary cilia in mature podocytes presumably is required to prevent the excessive influx of calcium ion. Some previous papers have reported that primary cilia were found on the mature podocytes in lower vertebrates (lamprey, sturgeon, and gilthead sea bream) (Miyoshi 1978; Ojéda et al. 2003; Zuasti et al. 1983), which exhibit extremely low GFR in comparison with birds and mammals (Braun and Dantzler 1997). This fact supports the above hypothesis that a high GFR is one of the factors inducing the primary cilia to disappear in podocytes.

The next issue is whether or not diseased podocytes re-express the primary cilia in adult mammals, since podocytes generally lose some phenotypes of differentiation under pathologic conditions (Shankland 2006). Kihara and colleagues have previously reported that the primary cilia were often found between the hyperplastic epithelial cells in idiopathic collapsing nephropathy (Kihara et al. 1997, 1999). These hyperplastic epithelial cells exhibit a swollen cell body, loss of cytoplasmic protrusions, and loss of actin-based cytoskeleton, and it is now believed that most of the hyperplastic epithelial cells are derived from dedifferentiated and proliferated podocytes (Albaqumi et al. 2006; Barisoni et al. 2009). Furthermore, Yoshikawa and colleagues reported that the primary cilia were found in the podocytes from three children with nephrotic syndrome (two with focal glomerular sclerosis, and one with minimal change nephrotic syndrome) (Yoshikawa et al. 1982). The primary cilia in the nephrotic children may reflect immaturity of glomeruli at childhood, rather than podocyte injury. We should thus investigate whether human podocytes express the primary cilia in intact immature and mature glomeruli and in a variety of glomerular diseases as future issues.

It is also controversial whether podocytes express the primary cilia in culture. Cultured podocytes lose various phenotypes found in the mature podocytes in vivo, and this phenomenon is regarded as dedifferentiation (Mundel et al. 1997). As shown in the present study, most immature podocytes express primary cilia, hence cultured podocytes are highly likely to express the primary cilia. Several researchers have previously reported that the polygonal cell type grown from isolated glomeruli was 

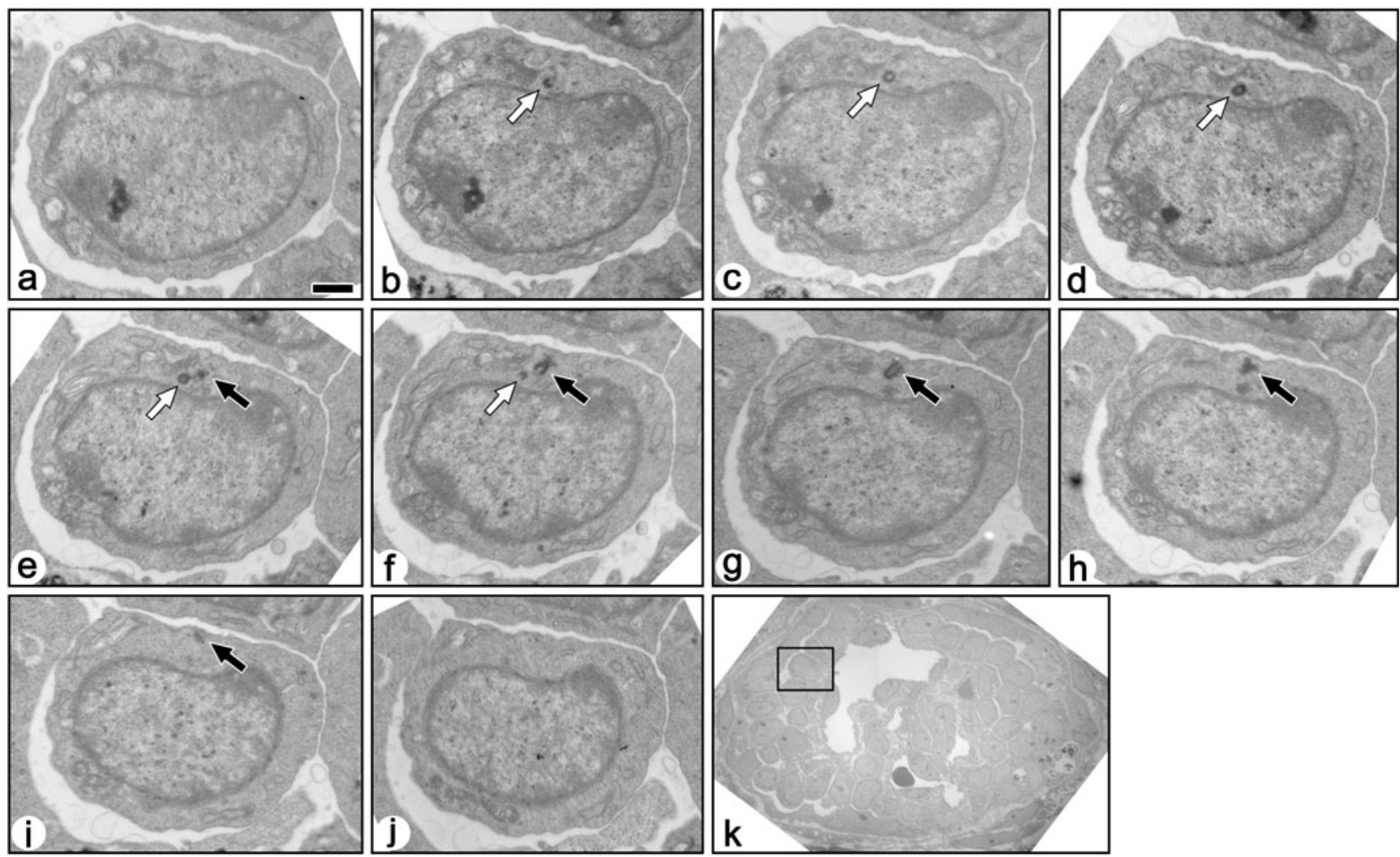

Fig. 9 Serial transmission electron micrographs of a non-ciliated immature podocyte in fetal rat $(\mathbf{a}-\mathbf{j})$. These sections include both mother (solid arrows) and daughter (open arrows) centrioles. The mother centriole is not in contact with the surface plasma membrane,

and no primary cilium was projected from the mother centriole. Bar $1 \mu \mathrm{m}$. $\mathbf{k}$ The podocyte shown by the serial sections is located in the rectangle

derived from podocytes and expressed the primary cilia (Kreisberg et al. 1978; Weinstein et al. 1992). However, Yaoita and colleagues indicated that there were two cell types derived from isolated glomeruli: polygonal and arborized cell types, and that only the arborized cell type, but not the polygonal, was derived from podocytes (Yaoita

et al. 2001; Yaoita et al. 1995). The arborized cell type was reported to express no primary cilium from the findings of SEM (Yaoita et al. 1995), but further investigation is required.

In conclusion, rat podocytes lose their primary cilia during glomerular development, and the primary cilium is

Fig. 10 Diagram showing that the primary cilia disappear in rat podocytes during glomerular development. In immature glomeruli of fetal rats, the podocytes express the primary cilia with high percentages.

However, in mature glomeruli of adult rats, the podocytes express no primary cilia

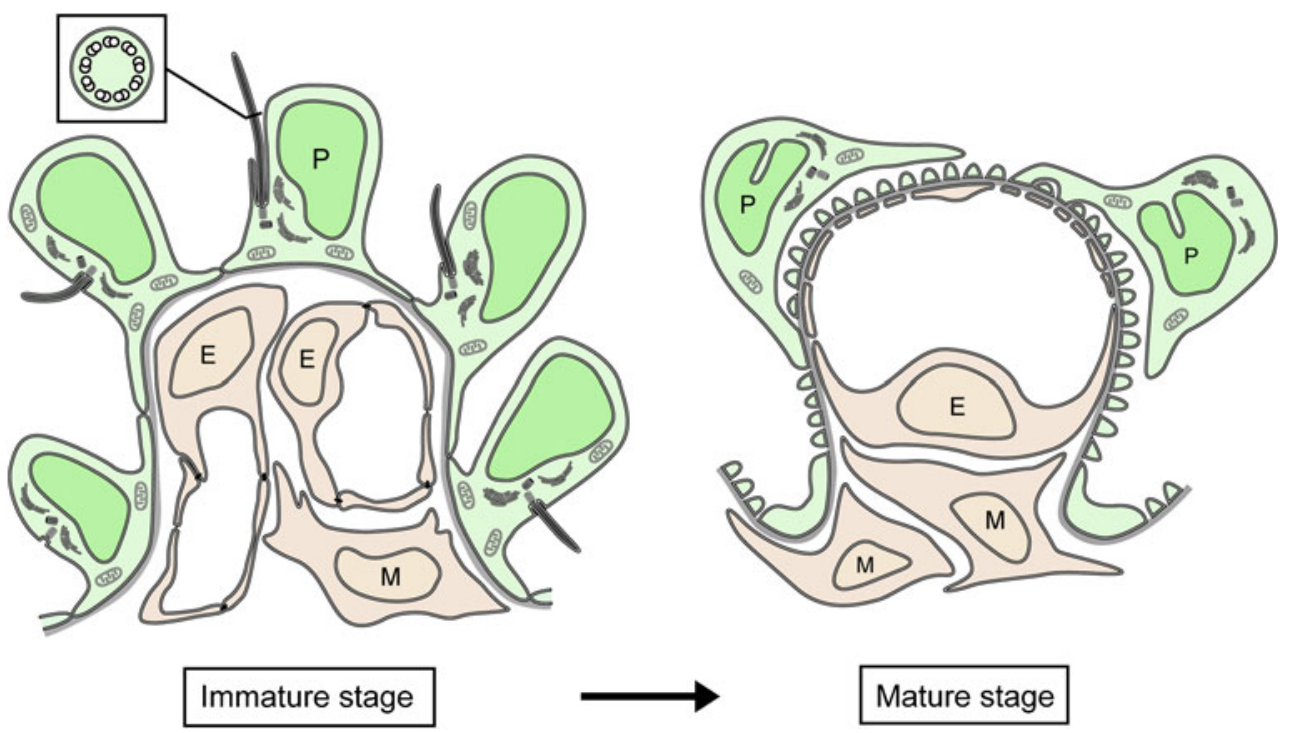


one of the characteristic features of podocyte immaturity. The mature podocytes in adult rats are exposed to strong shear stress by their larger GFR than that of lower vertebrates. The disappearance of the primary cilia presumably prevents the entry of excessive calcium via ciliumassociated calcium channels and the disturbance of intracellular signaling cascades in mature podocytes.

Acknowledgments The authors wish to thank Mr. Koichi Ikarashi for his skillful technical assistance in electron microscopy. This study was supported in part by a High Technology Research Center Grant from the Ministry of Education, Culture, Sports, Science and Technology of Japan (MEXT), and a Grant-in-Aid for Young Scientists (B) from MEXT (No.20790166 to K.I.).

\section{References}

Albaqumi M, Soos TJ, Barisoni L, Nelson PJ (2006) Collapsing glomerulopathy. J Am Soc Nephrol 17:2854-2863

Andrews PM (1975) Scanning electron microscopy of human and rhesus monkey kidneys. Lab Invest 32:510-518

Andrews PM, Porter KR (1974) A scanning electron microscopic study of the nephron. Am J Anat 140:81-115

Barisoni L, Schnaper HW, Kopp JB (2009) Advances in the biology and genetics of the podocytopathies: implications for diagnosis and therapy. Arch Pathol Lab Med 133:201-216

Braun EJ, Dantzler WH (1997) Vertebrate renal system. In: Dantzler WH (ed) Handbook of physiology, section 13. Comparative physiology, 1st edn. Oxford University Press, Oxford

Bulger RE, Siegel FL, Pendergrass R (1974) Scanning and transmission electron microscopy of the rat kidney. Am J Anat 139:483501

Bulinski JC (2007) Microtubule modification: acetylation speeds anterograde traffic flow. Curr Biol 17:R18-20

Elofsson R, Andersson A, Falck B, Sjoborg S (1984) The ciliated human keratinocyte. J Ultrastruct Res 87:212-220

Fukushima N, Furuta D, Hidaka Y, Moriyama R, Tsujiuchi T (2009) Post-translational modifications of tubulin in the nervous system. J Neurochem 109:683-693

Hagiwara H, Ohwada N, Aoki T, Suzuki T, Takata K (2008) The primary cilia of secretory cells in the human oviduct mucosa. Med Mol Morphol 41:193-198

Ichimura K, Kurihara H, Sakai T (2007) Actin filament organization of foot processes in vertebrate glomerular podocytes. Cell Tissue Res 329:541-557

Ichimura K, Kurihara H, Sakai T (2009) $\beta$-Cytoplasmic actin localization in vertebrate glomerular podocytes. Arch Histol Cytol 72:165-174

Karlsson U (1966) Three-dimensional studies of neurons in the lateral geniculate nucleus of the rat. I. Organelle organization in the perikaryon and its proximal branches. J Ultrastruct Res 16:429481

Khawaja S, Gundersen GG, Bulinski JC (1988) Enhanced stability of microtubules enriched in detyrosinated tubulin is not a direct function of detyrosination level. J Cell Biol 106:141-149

Kihara I, Tsuchida S, Yaoita E, Yamamoto T, Hara M, Yanagihara T, Takada T (1997) Podocyte detachment and epithelial cell reaction in focal segmental glomerulosclerosis with cellular variants. Kidney Int Suppl 63:S171-176

Kihara I, Yaoita E, Kawasaki K, Yamamoto T, Hara M, Yanagihara T (1999) Origin of hyperplastic epithelial cells in idiopathic collapsing glomerulopathy. Histopathology 34:537-547
Kobayashi T, Notoya M, Shinosaki T, Kurihara H (2009) Cortactin interacts with podocalyxin and mediates morphological change of podocytes through its phosphorylation. Nephron Exp Nephrol 113:e89-e96

Kreisberg JI, Hoover RL, Karnovsky MJ (1978) Isolation and characterization of rat glomerular epithelial cells in vitro. Kidney Int 14:21-30

Lu CJ, Du H, Wu J, Jansen DA, Jordan KL, Xu N, Sieck GC, Qian Q (2008) Non-random distribution and sensory functions of primary cilia in vascular smooth muscle cells. Kidney Blood Press Res 31:171-184

McGlashan SR, Jensen CG, Poole CA (2006) Localization of extracellular matrix receptors on the chondrocyte primary cilium. J Histochem Cytochem 54:1005-1014

Miyoshi M (1978) Scanning electron microscopy of the renal corpuscle of the mesonephros in the lamprey, Entosphenus japonicus Martens. Cell Tissue Res 187:105-113

Mundel P, Reiser J, Kriz W (1997) Induction of differentiation in cultured rat and human podocytes. J Am Soc Nephrol 8:697705

Nonaka S, Tanaka Y, Okada Y, Takeda S, Harada A, Kanai Y, Kido M, Hirokawa N (1998) Randomization of left-right asymmetry due to loss of nodal cilia generating leftward flow of extraembryonic fluid in mice lacking KIF3B motor protein. Cell 95:829-837

Ojéda JL, Icardo JM, Domezain A (2003) Renal corpuscle of the sturgeon kidney: an ultrastructural, chemical dissection, and lectin-binding study. Anat Rec A Discov Mol Cell Evol Biol 272:563-573

Palazzo A, Ackerman B, Gundersen GG (2003) Cell biology: Tubulin acetylation and cell motility. Nature 421:230

Poole CA, Zhang ZJ, Ross JM (2001) The differential distribution of acetylated and detyrosinated alpha-tubulin in the microtubular cytoskeleton and primary cilia of hyaline cartilage chondrocytes. J Anat 199:393-405

Reed NA, Cai D, Blasius TL, Jih GT, Meyhofer E, Gaertig J, Verhey KJ (2006) Microtubule acetylation promotes kinesin-1 binding and transport. Curr Biol 16:2166-2172

Rodat-Despoix L, Delmas P (2009) Ciliar functions in the nephron. Pflügers Arch 458:179-187

Ruffo A, Rossotto P, Motta G, Martines G, Musacci GF (1966) Ultrastructural findings in deep renal hypothermia. Minerva Med 57:3697-3721

Sasano Y (1986) Dynamic behavior of ciliated centrioles in rat incisor ameloblasts during cell differentiation. Arch Histol Jpn 49:437448

Satir P, Christensen ST (2007) Overview of structure and function of mammalian cilia. Annu Rev Physiol 69:377-400

Shankland SJ (2006) The podocyte's response to injury: role in proteinuria and glomerulosclerosis. Kidney Int 69:2131-2147

Veland IR, Awan A, Pedersen LB, Yoder BK, Christensen ST (2009) Primary cilia and signaling pathways in mammalian development, health and disease. Nephron Physiol 111:39-53

Verghese E, Weidenfeld R, Bertram JF, Ricardo SD, Deane JA (2008) Renal cilia display length alterations following tubular injury and are present early in epithelial repair. Nephrol Dial Transplant $23: 834-841$

Verghese E, Ricardo SD, Weidenfeld R, Zhuang J, Hill PA, Langham RG, Deane JA (2009) Renal primary cilia lengthen after acute tubular necrosis. J Am Soc Nephrol 20:2147-53

Wang L, Weidenfeld R, Verghese E, Ricardo SD, Deane JA (2008) Alterations in renal cilium length during transient complete ureteral obstruction in the mouse. J Anat 213:79-85

Weinstein T, Cameron R, Katz A, Silverman M (1992) Rat glomerular epithelial cells in culture express characteristics of parietal, not visceral, epithelium. J Am Soc Nephrol 3:1279-1287 
Wheatley DN (1982) The centriole: a central enigma of cell biology. Elsevier, Amsterdam

Wheatley DN (1995) Primary cilia in normal and pathological tissues. Pathobiology 63:222-238

Wheatley DN, Wang AM, Strugnell GE (1996) Expression of primary cilia in mammalian cells. Cell Biol Int 20:73-81

Yamamoto M, Kataoka K (1986) Electron microscopic observation of the primary cilium in the pancreatic islets. Arch Histol Jpn 49:449-457

Yaoita E, Yamamoto T, Takashima N, Kawasaki K, Kawachi H, Shimizu F, Kihara I (1995) Visceral epithelial cells in rat glomerular cell culture. Eur J Cell Biol 67:136-144
Yaoita E, Kurihara H, Sakai T, Ohshiro K, Yamamoto T (2001) Phenotypic modulation of parietal epithelial cells of Bowman's capsule in culture. Cell Tissue Res 304:339-349

Yoder BK (2007) Role of primary cilia in the pathogenesis of polycystic kidney disease. J Am Soc Nephrol 18:1381-1388

Yoshikawa N, Cameron AH, White RH (1982) Ultrastructure of the non-sclerotic glomeruli in childhood nephrotic syndrome. J Pathol 136:133-147

Zuasti A, Agulleiro B, Hernandez F (1983) Ultrastructure of the kidney of the marine teleost Sparus auratus: the renal corpuscle and the tubular nephron. Cell Tissue Res 228:99-106 